\title{
Microevolutionary processes in the creation of the Siberian species of carp
}

\author{
Elena Pishchenko ${ }^{1 *}$, Irina Moruzi ${ }^{1}$, Liudmila Zakonova $^{2}$, Liubov Vesnina ${ }^{3}$, and Dmitrii \\ Kropachev ${ }^{1}$ \\ ${ }^{1}$ Novosibirsk State Agrarian University, Dobrolyubova st., 160, Novosibirsk, 630039, Russia \\ ${ }^{2}$ Branch of KuzSTU in Belovo, Inskoy, Ilyicha st., 32-A, Belovo, Kemerovo region, 652644, Russia \\ ${ }^{3}$ Institute for Water and Environmental Problems, Siberian Branch of Russian Academy of Sciences, \\ 3, Molodezhnaya st., Barnaul, Altai Krai, 656038, Russia
}

\begin{abstract}
Selection of carp was started in 1964 in Siberia. The work was carried out in a continental climate. The duration of the winter period was 120-130 days. The species was created by the method of mass directed selection in terms of body growth, girth and fecundity. In comparison with the original population, the body weight of females in the average school increased significantly - by $67.17 \%$, and the weight of female five-yearolds - by $33.58 \%$. This led to earlier maturation and accelerated the generational change. Considering the dynamic series of the exterior of the females according to the indices of progonism, broad-back, body girth, as well as exterior profiles, we noted that the population of the Altai mirror carp had a high growth rate, which ensured high fish productivity of reservoirs. Analysis of the variability of morphological traits from the third to the seventh generation showed that against the background of a noticeable increase in body weight, body length decreased, girth, growth and thickness increased. The body of the Altai mirror carp for five generations of breeding has become more compact, the exterior has improved.
\end{abstract}

\section{Introduction}

Genetic improvement of cultured fish plays an important role in optimizing and increasing aquaculture production [1-3]. The common carp (Cyprinus carpio) is one of the most widely farmed fish species in the world. In 2018, the volume of its farming in the world reached 4,189 million tons [4]. In the recent past, many studies have been conducted concerning the genetic improvement of carp [5-8]. Studies on the genetic marking of carp should be highlighted $[9,10]$.

In contrast to salmon species, selective breeding programs are not often implemented for carp. Breeding programs for this species are generally characterized by the development of different strains that are used for crossing [11, 12]. That is due to the high level of heterosis in terms of the signs associated with the growth rate [13]. This may explain why much attention is paid to crossbreeding with this species. Most of the observed heterosis is

\footnotetext{
${ }^{*}$ Corresponding author: epishenko@ngs.ru
} 
most likely caused by the fact that the parent strains are highly inbred. It is inbreeding that causes a decrease in efficiency on the grounds of productivity and resistance to diseases. In addition, the holding of separate lines adds additional costs. Selective breeding is a traditional genetic technology that permits the accumulation of genetic gain in each generation. It is a good long-term, and often a highly cost-effective, strategy for strain improvement and domestication [1, 14]. Genetic improvements in traits by selective breeding produce genetic gains of about $10 \%$ generation [2]. Most studies have focused on production characteristics such as growth rate and fish productivity (yield) [13, 15]. More recently, Vandeputte et al. reported a heritability of $0.49-0.63$ for body weight and 0.36 yield [16]. In Russia, when breeding carp, it is believed that the stagnation of the productive properties of carp is achieved in the seventh $\left(\mathrm{F}_{7}\right)$, eighth $\left(\mathrm{F}_{8}\right)$ generation, while the influence of inbreeding is not observed. This is achieved by a proper breeding plan in carp populations.

In Western Siberia, selection and breeding work with fish populations (carp and trout) was started in the 60 s of the XX century and has been actively continuing to the present day. It is aimed at creating breeds that are well adapted to the conditions of a sharply continental climate. Carp (Ciprinus carpio, L.) is a species introduced to Western Siberia in 1928.

The purpose of the introduction is commercial rearing in the lakes of Western Siberia, since there are no other fast-growing fish species in the natural ichthyofauna. However, there was a lot of doubts that the species would be able to adapt to the climatic conditions of southern Siberia, due to the long wintering conditions (6 months) in reservoirs at a temperature of $0^{\circ} \mathrm{C}$. As a result of the first introduction under the leadership of $\mathrm{B}$. G. Johansen (1928), about 42,316 yearlings of leather and mirror carp were transported and put in Lake Sartlan in the Novosibirsk region. This work was not successful, but individual specimens were found in the lake until 1934.

There are several reasons for this. Once every 3-5 years, in winter, the oxygen level in Lake Sartlan is extremely low, there is fish starvation. The water balance of this lake is associated with the accumulation of spring surface water, and spawning becomes impossible by the time the water warms up to spawning temperatures, the overflow waters have time to come down and there is no freshly flooded vegetation in the inshore zone. However, in 1932, the research was repeated. Galician carps were taken for the introduction from Moldova, and was gradually acclimatized in the reservoirs of Central Russia and the Urals. Carps were introduced to various lakes and ponds of the Altai Krai. From 1940 to 1964, these populations existed under the conditions of natural selection and panmixia. Thus, the natural acclimatization of carp to the climate conditions of the south of Western Siberia was carried out.

Work on the development of fish farming in Siberia was started in the early 60s of the XX century. This work required the creation of a highly productive carp population. In 1964, 46 females and 74 males of mirror carp aged 2-3 years were caught from one pond located on the territory of the Altai Krai. They served as the starting material for the creation of the Altai mirror carp breed. By that time, the fish had gone wild. The shape of their body deviated to the wild type: the height of the body and girth decreased, the speed increased. The fecundity was 25.5-75.0 thousand eggs $(\mathrm{Cv}=56 \%)$ per female at the age of 5 years. In 1996, as a result of breeding, the Altai mirror carp breed was created. Until now, it is preserved and on its basis, the selection of the breed type continues. Another group of carp from a feral population, living in the reservoirs of the Kemerovo region, became the material for breeding carp grown in the conditions of a warm-water cage farm. This breed is known as Belovsky carp. Currently, breeding in carp populations is aimed at preserving and increasing carp's own productivity. Selection is carried out to increase the growth rate and fecundity of fish and survival at the first stages of development. 
The aim of the research is to study the microevolutionary processes in the creation of Siberian carp breeds.

\section{Materials and methods}

During acclimatization of carp in the Altai Krai and 32 years of natural selection, with panmixia, there was continuous intrapopulation hybridization with complex breakdown, emergence of homozygotes and heterozygotes. Therefore, during mass selection in the populations of the Altai mirror carp, a high level screening of fishes that do not correspond to the desired type was conducted.

Mass selection, aimed at increasing the growth rate in breeding populations of the Altai mirror carp, begins at the end of the first growing season (fingerlings) or at the beginning of the second season (yearlings). Fishes are selected for further crossbreeding according to the assessment of body traits and the degree of compliance with breed standards. When forming redds for breeding, the 2:1 ratio of males and females, class affiliation, age, weight and quality of sperm are taken into account, for re-spawning females - fertility. For our analysis we calculated the following body condition indices: 1) relation of the absolute length of the body to the greatest height of the body (length-height, $1 / \mathrm{H}) ; 2$ ) percentage ratio of the maximum girth of the body to body length until the end of scale covering (girth body length, U/1*100); 3) percentage ratio of the greatest body width to body length until the end of scale covering (body width - body length, B/1*100).

\section{Results and discussion}

The analysis of the exterior was carried out for fishes of different ages and three generations of breeding. The obtained results prove that under the influence of selection, the body shape of carps has changed, and the variability of the characteristics of the selected ones has decreased.

The coefficient of variation in body weight of fingerlings of the Altai carp $F_{3}$ was 41.2. By the seventh generation $\left(\mathrm{F}_{7}\right)$, the level of variability in fingerlings by body weight decreased to $25.9 \%$.

Simultaneously with the increase in body weight in carp fingerlings, there was an increase in length, height, thickness and girth of the body. The most increased were body height, girth and thickness - by $28.5 \%, 27.9 \%$ and $24.0 \%$ respectively. The length of the body increased by $11.2 \%$, which is less than in other indicators. At the same time, there was a decrease in the coefficient of variation in body girth by $37 \%$. The level of variability in body height and length also significantly decreased - by $30.7 \%$ and $27.0 \%$, respectively. Of all the body condition indices we calculated, the greatest changes are observed for the girth - body length ratio. There was an increase in its value by $15.71 \%$ (Table 1). At the same time, the fineness ratio (length-height) decreased by $14.3 \%$ and the body width - body length ratio increased by $11.5 \%$. Together, these changes indicate a significant change in the appearance of the fingerlings. They become less long and more wide. 
Table 1. Body condition indices of fishes of different age.

\begin{tabular}{|c|c|c|c|c|}
\hline \multirow{2}{*}{ Indicator } & \multirow{2}{*}{$\begin{array}{c}\text { Fulton's } \\
\text { condition factor }\end{array}$} & \multicolumn{3}{|c|}{ Body condition indices } \\
\hline & & $l / H$ & $\mathrm{~B} / 1 * 100$ & $\mathrm{U} / 1 * 100$ \\
\hline \multicolumn{5}{|c|}{$F_{3}$} \\
\hline $\bar{x} \pm s_{\bar{x}}$ & $2.26 \pm 0.10$ & $2.94 \pm 0.05$ & $16.45 \pm 0.30$ & $83.82 \pm 1.52$ \\
\hline $\mathrm{CV}$ & 28.4 & 12.1 & 12.0 & 12.0 \\
\hline \multicolumn{5}{|c|}{$\overline{F_{7}}$} \\
\hline $\bar{x} \pm s_{\bar{x}}$ & $2.89 \pm 0.06$ & $2.53 \pm 0.03$ & $18.34 \pm 0.29$ & $96.99 \pm 0.72$ \\
\hline $\mathrm{CV}$ & 14.9 & 8.2 & 11.3 & 5.3 \\
\hline
\end{tabular}

The coefficient of variation significantly decreased for the body girth index (from $12.0 \%$ to $5.3 \%$ ), the finesse ratio (from 12.0 to 8.2 ) and the coefficient of condition (almost by half).

Over five generations of breeding, the mass of fingerlings has significantly increased: if in $\mathrm{F}_{3}$ the diversity of fish by body weight was from 9 to $42 \mathrm{~g}$, in $\mathrm{F}_{7}$ it was from 20.5 to $56 \mathrm{~g}$. A high concentration of variants is noted on the right side of the curve in $F_{3}$ and $F_{7}$ populations. The variation curve has a right-sided asymmetry due to the elongation of the right branch of the curve. At the same time, fast-growing specimens in $\mathrm{F}_{3}$ had a weight of $27.5-42 \mathrm{~g}$ and accounted for $25 \%$ of the population. During the selection process, the number of fast-growing specimens increased to $43 \%$ in the population. Their weight has also increased and is in the range from 37 to $56 \mathrm{~g}$. It should be noted that there is a high concentration of fishes in the modal and near modal classes up to $82.7 \%$ and $83.3 \%$ (Fig. $1)$.
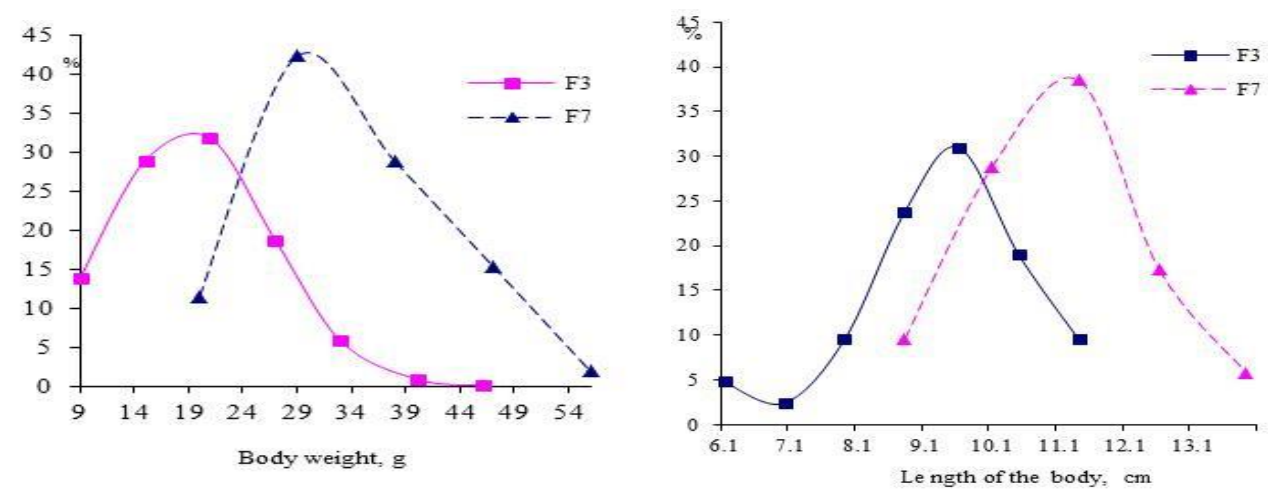

Fig.1. Polygons of distribution of fishes by weight and length.

$\mathrm{F}_{7}$ fingerlings have a large average weight of $33.1 \mathrm{~g}$ (normal distribution, $\chi^{2}=2$, with $\chi^{2} \mathrm{st}=3.8$ ). The polygon of their distribution by body weight is more stretched along the $Y$ axis than in fishes of the third generation of selection. Its curve has closer branches and is shifted to the right by two classes. The asymmetry coefficient of the curve is 0.785 .

In the third generation of selection, fish of the modal and adjacent classes accounted for $72.8 \%$ of the total population. Based on this, we can say that there was a small group $(1.3 \%)$ of slowly growing fish in the $\mathrm{F}_{3}$ population. There were about $3 \%$ of fish in the $\mathrm{F}_{3}$ selection group with a mass of 34.5-42 $\mathrm{g}$, in $\mathrm{F}_{7}-8 \%$ with a body weight of 50-59 $\mathrm{g}$. The polygon of body length distribution in the third generation is unimodal.

The asymmetry coefficient is -0.68 , i.e. the curve has a left-sided asymmetry and differs in shape from the normal distribution curve quite strongly. Fish of the modal and adjacent 
classes made $83.3 \%$ of the total number. The population contained a small group of slowgrowing fish, which is confirmed by left-sided asymmetry.

In fingerlings of the seventh breeding generation, the polygon of body length distribution is also distinguished by an increased concentration of individuals in the modal and adjacent classes. Their number is $84.6 \%$ of the total population. Right-sided asymmetry of the curve (asymmetry coefficient +1.1 ) indicates the appearance of a small group of fish with an increased growth rate $\left(\chi^{2}=3, \chi^{2}=\{7.8-11.3-16.3\}\right)$.

Variational curves of body weight and length of the seventh generation of Altai mirror carp are distinguished by the closeness of branches. They are more symmetric and have a greater concentration of variants in the modal and near modal classes. This character of the curves proves that selection breeding over a number of generations has led to greater uniformity and evenness of the population.

In the course of many years of work with a herd of Altai mirror carp, selecting the population by body weight and fecundity, we noted a change in the exterior indices. The following changes occurred in the populations of mature fish aged 4-7 years. The study of the total body weight of brood stock on average for the population without taking into account age showed that the body weight $(Q)$ increased by $67.17 \%$ over five generations $(\mathrm{p}>0.999)$. At the same time, the body length $(l)$ slightly increased - by $3.10 \%(\mathrm{p}>0.999)$. The height $(H)$ of the body, on the contrary, changed significantly - by $21.61 \%$ ( $>0.999)$. Together, these changes indicate a change in body shape. The thickness $(B)$ and girth $(U)$ of the body changed evenly, increasing by $14.7 \%$. The coefficient of variation for body weight decreased significantly by 1.53 . The changes are insignificant for other indices. Over five generations, there was a decrease in the fineness ratio by $18.15 \%(p>0.999)$, and the values of the girth - body length and width-length ratios increased by $10.94 \%$ and $11.12 \%$, respectively (Table 2).

Table 2. Body condition of $F_{3}$ and $F_{7}$ females in the whole population without taking into account age.

\begin{tabular}{|c|c|c|c|}
\hline \multirow{2}{*}{ Indicator } & \multicolumn{3}{|c|}{ Body condition indices } \\
\cline { 2 - 4 } & $l / H$ & $\mathrm{~B} / 1^{*} 100$ & $\mathrm{U} / 1^{*} 100$ \\
\hline $\bar{x} \pm s_{\bar{x}}$ & $3.19 \pm 0.03$ & $20.47 \pm 0.18$ & $84.65 \pm 0.71$ \\
\hline $\mathrm{Cv}$ & 9.6 & 9.1 & 8.8 \\
\hline \multicolumn{4}{|c|}{$\mathrm{F}_{7}$} \\
\hline $\bar{x} \pm s_{\bar{x}}$ & $2.70 \pm 0.02$ & $22.71 \pm 0.18$ & $94.09 \pm 0.66$ \\
\hline $\mathrm{Cv}$ & 7.1 & 7.7 & 6.7 \\
\hline
\end{tabular}

It is known that in fish, sexual maturity depends on the weight and length of the body. Therefore, mass selection aimed at increasing of body weight has led to a decrease in the reproductive age. Under the influence of selection conducted from $F_{3}$ to $F_{7}$, the age of females transferred to the main population decreased from 5 to 4 years. The weight of $F_{3}$ females at the age of 4 years was $2541.9 \mathrm{~g}$, and not all of them reached sex maturity by this age.

In the third generation of selection, fishes were transferred to the main population, at the age of 5 years with a mass of $3298.8 \mathrm{~g}$. The fish of the seventh generation of selection significantly exceed their peers in weight and at the age of 4 years have a weight of 4452.9 g. They first participate in spawning at this age. Simultaneously with the selection by weight, the body height was also taken into account, as a result of which there was an increase in this indicator. In four-year-old fishes, it increased on average by $24.36 \%$ ( $>0.99$ ), while the coefficient of variation remained at the same level. 
Despite the fact that the thickness and girth of the body were only taken into account during the selection, there was an increase in these indices by $16.01 \%$ and $19.70 \%$, respectively. The variability of body weight decreased most of all - from 11.3 to 4.6 $(p>0.99)$. The change in this coefficient is insignificant for the other indicators of the phenotype.

The study of relative body composition indicators showed that four-year-old females of the third and seventh generations of breeding do not differ significantly from each other according to the index of body width - length $\left(B / l^{*} 100\right)$. During the selection process, the length-height ratio $(1 / \mathrm{H})$ decreased by $21.34 \%$, and the body width - length ratio $\left(\mathrm{B} / 1^{*} 100\right)$ increased by $18.1 \%$ (Table 3 ).

Table 3. Indices of the exterior of females of different ages.

\begin{tabular}{|c|c|c|c|c|c|c|c|c|}
\hline \multirow{2}{*}{ Indicator } & \multicolumn{7}{|c|}{ Four-Year-Olds } & \multicolumn{4}{c|}{ Five-Year-Olds } \\
\cline { 2 - 9 } & $l / H$ & $\mathrm{~B} / 1 * 100$ & $\mathrm{U} / 1 * 100$ & $l / H$ & $l / H$ & $\mathrm{~B} / 1 * 100$ & $\mathrm{U} / 1 * 100$ & $l / H$ \\
\hline \multicolumn{7}{|c|}{$\mathrm{F}_{3}$} \\
\hline $\bar{x} \pm S_{\bar{x}}$ & $2.75 \pm 0.02$ & $3.24 \pm 0.05$ & $20.24 \pm 0.29$ & $83.77 \pm 1.17$ & $2.85 \pm 0.02$ & $2.87 \pm 0.01$ & $22.22 \pm 0.10$ & $89.17 \pm 0.46$ \\
\hline $\mathrm{Cv}, \%$ & 9.2 & 10.0 & 9.5 & 9.2 & 8.6 & 4.4 & 4.3 & 5.1 \\
\hline \multicolumn{8}{|c|}{$\mathrm{F}_{7}$} \\
\hline $\bar{x} \pm S_{\bar{x}}$ & $3.24 \pm 0.03$ & $2.67 \pm 0.06$ & $22.92 \pm 0.49$ & $97.86 \pm 2.26$ & $3.54 \pm 0.07$ & $2.62 \pm 0.04$ & $22.81 \pm 0.33$ & $94.92 \pm 0.89$ \\
\hline $\mathrm{Cv}, \%$ & 9.8 & 9.0 & 8.8 & 9.5 & 6.7 & 5.6 & 4.8 & 3.1 \\
\hline
\end{tabular}

When constructing the polygons of the distribution of the weight and length of the body of the third generation, the bimodal ratio is clearly expressed (Fig. 2). This allowed us to assume that a group $(24.1 \%)$ of fast-growing specimens formed in the fish population. Fish from this group were left for reproduction during the selection aimed at increasing the growth rate. As a result, by the seventh generation of breeding, the weight of fish at the age of five years increased and ranged from 4800 to $5200 \mathrm{~g}$ and averaged $4927.2 \mathrm{~g}$. The polygon has a high frequency concentration in the modal and adjacent classes $(84.2 \%)$. The branches of the curve are close together. The second vertex disappeared. The population became more consolidated in weight and there was a shift of the modal class of the curve relative to the third generation by 4 classes to the right.

A bimodal pattern was noticed in fishes of the third generation of selection, when studying the polygon of the body length distribution. This confirmed the formation of a group of fast-growing fish. The concentration of fishes in the modal and near-modal classes was $46.4 \%$. In a population of fish of the seventh generation of selection, the distribution polygon on the basis of body length is unimodal. The curve is more stretched along the ordinate axis compared to the curve for the third generation of breeding. The concentration of specimens in the modal and adjacent classes is quite high $-75.4 \%$. This distribution is typical for the population in which the selection is taking place, and confirms the effectiveness of the selection aimed at increasing the body weight. 

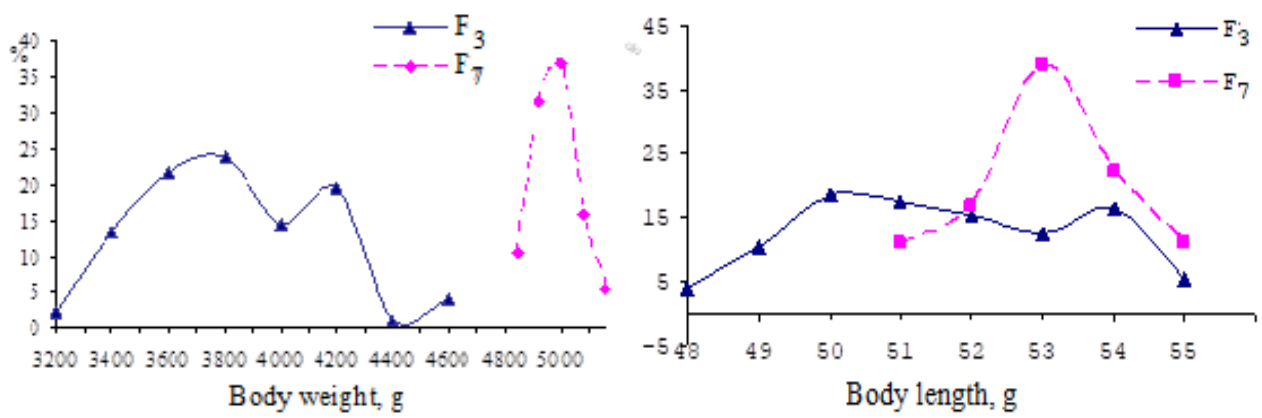

Fig. 2. Polygon of distribution of $F_{3}$ and $F_{7}$ five-year-old females by body weight and body length.

\section{Conclusions}

The Altai mirror carp population during the breeding period from 1964 to 1998 underwent adaptation to the sharply continental climate of Siberia, as evidenced by the high growth rate. This indicator is within the limits of the species and provides a high fish productivity of reservoirs.

\section{References}

1. FAO. Commission on Genetic Resources for Food and Agriculture assessments, Rome (2019), http://www.fao.org/3/ca5256en/CA5256EN.pdf

2. T. Gjedrem, N. Robinson, M. Rye, Aquaculture, 350-353, 117-129 (2012), doi: 10.1016/j.aquaculture.2012.04.008.

3. T. Gjedrem, Aquaculture, 344, 12-22 (2012), doi:10.1016/j.aquaculture.2012.03.003

4. FAO. The State of World Fisheries and Aquaculture 2020. Sustainability in action, Rome (2020), doi: 10.4060/ca9229en

5. N. H. Ninh, R. W. Ponzoni, N. H. Nguyen, et al., Aquaculture, 322-323, 39-46 (2011), doi: 10.1016/j.aquaculture.2011.09.031

6. Z. Dong, N. H. Nguyen, W. Zhu, BMC Genet., 16, 94 (2015), doi: 10.1186/s12863015-0256-2

7. M. Prchal, J. Bugeon, M. Vandeputte, et al., Frontiers in Genetics, 9, 283 (2018), doi: 10.3389/fgene.2018.00283

8. B. Gomelsky, Biology and ecology of carp (Boca Raton, 2015)

9. Ch. Palaiokostas, M. Kocour, M. Prchal, R.D. Houston, Front. Genet., 9, 82 (2018), doi: 10.3389/fgene.2018.00082

10. A. V. Nedoluzhko, N. V. Slobodova, F. Sharko, et al., Ecol. Evol., 10, 5431- 5439 (2020), doi: 10.1002/ece3.6286

11. J.-A. Hwang, I. B. Goo, J. E. Kim, et al., Dev. Reprod., 20(4), 275-281 (2016), doi:

12. H. M. Nielsen, J. Ødegård, I. Olesen, et al., Aquaculture, 304(1-4), 14-21(2010), doi: 10.1016/j.aquaculture.2010.03.016.

13. M. Yousefian, M. Sharifrohani, H. Hosseinzadeh, Iranian Journal of Fisheries Sciences, 10(4), 740-748 (2011), doi:10.12717/DR.2016.20.4.275

14. T. Gjedrem, N. Robinson, Agricultural Sciences, 5, 1152-1158 (2014), doi:10.4236/as.2014.512125. 
15. N. H. Ninh, R. W. Ponzoni, N. H. Nguyen, et al., Aquaculture 40, 152-159. (2013) doi: 10.1016/j.aquaculture.2013.06.005

16. M. Prchal, A. Kause, M. Vandeputte, et al., PLoS ONE 13(1), e0191624 (2018) doi: 10.1371/journal.pone.0191624 